\title{
Chromium removal from industrial wastewater using Phyllostachys pubescens biomass loaded Cu-S nanospheres
}

https://doi.org/10.1515/chem-2018-0073

received March 20, 2018; accepted May 9, 2018.

\begin{abstract}
In this paper, a new surface modification method was reported for the preparation of Phyllostachys pubescens powder as an effective adsorbent for the removal of chromium. Complex copper sulfide (Cu-S) nanospheres were evenly dispersed and loaded into the internal surface of the adsorbent, which provided both the ion exchange and oxidative-reductive properties. The composite showed an excellent adsorption efficacy for $\mathrm{Cr}(\mathrm{III})$ and $\mathrm{Cr}(\mathrm{VI})$. The surface properties of the obtained materials were characterized by FTIR and SEM. Maximum adsorption for $\mathrm{Cr}(\mathrm{III})$ and $\mathrm{Cr}(\mathrm{VI})$ was observed at $\mathrm{pH} 6.1$ and 1.9, respectively. The experimental sorption equilibrium data were modeled using Langmuir and Freundlich isotherm equations. It was found that the maximum adsorption capacities of $\mathrm{Cr}(\mathrm{III})$ and $\mathrm{Cr}(\mathrm{VI})$ were $52.30 \mathrm{mg} \mathrm{g}^{-1}$ and 94.25 $\mathrm{mg} \mathrm{g}^{-1}$, respectively. The adsorption mechanism analysis inferred that the major adsorption mode of $\mathrm{Cr}$ (III) was ion exchange, and $\mathrm{Cr}(\mathrm{VI})$ was oxide-reduction.
\end{abstract}

Keywords: Phyllostachys pubescens, chromium removal, copper sulfide, adsorption

\section{Introduction}

Throughout the world, heavy metals are one of the most widespread origin of industrial water pollution, because of their toxicity, non-biodegradable nature and accumulation in living organisms [1-3]. Chromium is such a major toxic heavy metal for both humans and the environment and

\footnotetext{
*Corresponding author: Xiaojun Jiang, School of Chemical Engineering, University of Science and Technology Liaoning, Anshan 114051, PR China, E-mail: asjiangxiaojun@163.com Tian Ai: School of Chemical Engineering, University of Science and Technology Liaoning, Anshan 114051, PR China

Qingyu Liu: College of Engineering, Shenyang Agricultural University, Shenyang 110161, PR China
}

often found in industrial wastewater, which is introduced into water streams from mining, tanning, electroplating, wood preservatives, paints, textile dyeing, and plants producing industrial inorganic chemicals and pigments $[4,5]$. Chromium occurs most frequently as both trivalent [Cr(III)] and hexavalent [Cr(VI)] states in aquatic environment. Trace amounts of $\mathrm{Cr}(\mathrm{III})$ is an essential micronutrient for sugar, protein and fat metabolism in mammals, while $\mathrm{Cr}(\mathrm{VI})$ is a primary contaminant, which is considered potential carcinogen that induces primary liver cancer [6,7]. Hence, it is necessary to treat industrial wastewater containing chromium before being discharged to the environment.

Conventional treatment methods such as electrochemical precipitation [8], ion exchange [9], membrane processing [10], solvent extraction [11], coagulation [12], and adsorption [13] have been employed to remove chromium from wastewater. Among all these techniques, adsorption as one of the effective and versatile method for removing chromium from wastewater at relatively low concentrations and has been widely studied during recent decades [14]. Many kinds of adsorbents have been tested by researchers for removal of chromium from aqueous solution. Up to now, activated carbon is the most widely used adsorbent due to its high efficiency and easy recovery, but its price is relatively high, which limits its use as an adsorbent in developing countries like China. Hence, the use of low-cost materials as adsorbents, and improving their adsorption efficiency have been the directions and focuses of many researchers. In recent years, agricultural waste materials have become widely used as adsorbents due to their cheap prices, renewable, abundance in nature, large surface area and high adsorption capacity. A large number of literature have been studied for the removal of both $\mathrm{Cr}(\mathrm{III})$ and $\mathrm{Cr}(\mathrm{VI})$ using various agricultural wastes. Barrera et al. [15]. investigated for the removal Cr(III) and $\mathrm{Cr}(\mathrm{VI})$ from aqueous solutions by natural, protonated and thermally treated Ectodermis of Opuntia. Fiol et al. [16]. reported a study for the removal of $\mathrm{Cr}(\mathrm{III})$ and $\mathrm{Cr}(\mathrm{VI})$ using grape stalks and yohimbe bark wastes. The results 
of batch experiments demonstrated that both sorbents are able to reduce $\mathrm{Cr}(\mathrm{VI})$ to its trivalent form. Elangovan et al. [17]. used different aquatic weeds (reed mat, water lettuce, arrow-leaved tear thumb, lotus flower, green taro, water lily flower, water hyacinth and mangrove leaves ) as biosorbents for $\mathrm{Cr}(\mathrm{III})$ and $\mathrm{Cr}(\mathrm{VI})$ removal from aqueous phase. The results show that chemical treatment with $\mathrm{H}_{2} \mathrm{SO}_{4}$ significantly increased $\mathrm{Cr}(\mathrm{VI})$ removal capacity of the biosorbents. Romero-Gonzalez et al. [18]. studied sorption of $\mathrm{Cr}(\mathrm{III})$ and $\mathrm{Cr}(\mathrm{VI})$ on Agave lechuguilla from aqueous solutions. The authors showed $\mathrm{Cr}(\mathrm{III})$ adsorption followed Langmuir isotherm model, while $\mathrm{Cr}(\mathrm{VI})$ followed the Freundlich model. Abbas et al. [19]. also studied the removal of $\mathrm{Cr}(\mathrm{III})$ and $\mathrm{Cr}(\mathrm{VI})$ by Cassia fistula under different experimental conditions $(\mathrm{pH}$, initial metal concentration, dose, size, time and temperature). The authors reported that the adsorption followed the pseudosecond-order kinetic model and Langmuir isotherm model, and maximum adsorption of $\mathrm{Cr}(\mathrm{III})$ was at $\mathrm{pH} 5$ and $\mathrm{Cr}(\mathrm{VI})$ at $\mathrm{pH} 2$.

In our earlier paper [20], we used $P$. pubescens powder as $\mathrm{Cu}$ (II) biosorbent after chemical modification with mercaptoacetic acid. The results suggested that the thiol-modified P. pubescens powder is more favorable for adsorption of metal ions with positive charge. Based on the above work, this paper does some research on removal of $\mathrm{Cr}(\mathrm{III})$ and $\mathrm{Cr}(\mathrm{VI})$. Firstly, a large number of thiol functional groups were introduced on the surface of the adsorbent. The copper ion was initially immobilized on the surface of the adsorbent via thiol groups, then an excess of $\mathrm{S}^{2-}$ was added to form $\mathrm{Cu}-\mathrm{S}$ nanospheres, which precipitated and evenly distributed on the internal surface of the adsorbent. In other words, this method simultaneously accomplished the removal of $\mathrm{Cu}$ (II) and the preparation of the adsorbent.

The main objective of this study was to develop innovative and efficient technology for the removal of chromium ions from industrial electroplating wastewater and tanning wastewater with different components, and systematically investigate the adsorption properties of $\mathrm{Cr}(\mathrm{III})$ and $\mathrm{Cr}(\mathrm{VI})$ by the modified P. pubescens powder. For this purpose, the experiments were done in a batch system and the effects of $\mathrm{pH}$, contact time and initial metal concentration on the removal of $\mathrm{Cr}(\mathrm{III})$ and $\mathrm{Cr}(\mathrm{VI})$ were described here in detail. The kinetics parameters were also determined and compared. Furthermore, Langmuir and Freundlich isotherm models were used to describe adsorption equilibrium data, and the probable adsorption mechanisms for chromium ions at adsorbent-solution interface were also explained. In addition, adsorptiondesorption experiments were performed with the industrial electroplating wastewater and tanning wastewater containing low concentrations of chromium in order to determine the practicality of this novel adsorbent material.

\section{Experimental}

\subsection{Reagents}

All chemicals used in this study were of analytical reagent grade. The stock solutions (1000 $\left.\mathrm{mg} \mathrm{L}^{-1}\right)$ of $\mathrm{Cr}$ (III) and $\mathrm{Cr}(\mathrm{VI})$ were prepared by dissolving $\mathrm{Cr}\left(\mathrm{NO}_{3}\right)_{3} \cdot 9 \mathrm{H}_{2} \mathrm{O}$ and $\mathrm{K}_{2} \mathrm{Cr}_{2} \mathrm{O}_{7}$ in $1 \mathrm{~L}$ of double distilled water (DDW). Desired $\mathrm{Cr}(\mathrm{III})$ and $\mathrm{Cr}(\mathrm{VI})$ solutions of different concentrations for each test were prepared by adequate dilution of stock solution with DDW. The $\mathrm{pH}$ of the solutions was adjusted by the addition of $0.1 \mathrm{~mol} \mathrm{~L}^{-1} \mathrm{HCl}$ and $0.1 \mathrm{~mol} \mathrm{~L}^{-1} \mathrm{NaOH}$.

\subsection{Preparation of the biosorbent}

In the present investigation, $P$. pubescens powder (PPP) was purchased from a moso bamboo fabricating plant of Lishui, Zhejiang, China. The PPP was washed with DDW several times, and dried in a convection oven at $105^{\circ} \mathrm{C}$ for $24 \mathrm{~h}$. The obtained product was sieved through an 80mesh $(0.180 \mathrm{~mm})$ sieve.

About $25 \mathrm{~g}$ of dried PPP was dipped in $250 \mathrm{~mL} 0.1 \mathrm{~mol}$ $\mathrm{L}^{-1} \mathrm{NaOH}$ solution and stirred at $120 \mathrm{r} \mathrm{min}^{-1}$ at $25^{\circ} \mathrm{C}$ for 24 h. Then obtained sample was washed with DDW until the $\mathrm{pH}$ of solution reached neutral, and dried at $70^{\circ} \mathrm{C}$ for 24 h. Hereafter, abbreviated as PPP-OH. About $5 \mathrm{~g}$ of PPP-OH was then suspended in $125 \mathrm{ml}$ of $10 \%$ mercaptoacetic acid at $25^{\circ} \mathrm{C}$ for $24 \mathrm{~h}$. The obtained sample is abbreviated as PPP-SH. After acid reaction, PPP-SH were dipped in $15 \mathrm{ml}$ of $0.025 \mathrm{~mol} \mathrm{~L}^{-1}$ cupric sulfate solution. Next, 30 $\mathrm{ml}$ of $0.05 \mathrm{~mol} \mathrm{~L}^{-1}$ sodium sulfide solution was added dropwise to the mixture. The reaction was stirred at $120 \mathrm{rpm}$ at $25^{\circ} \mathrm{C}$ for $6 \mathrm{~h}$, and thereafter still continues stirring at $75^{\circ} \mathrm{C}$ for $1 \mathrm{~h}$. Finally, the adsorbents were then washed several times thoroughly with $200 \mathrm{ml}$ DDW until the $\mathrm{pH}$ reached nearly neutral $(7 \pm 0.5)$ and then dried at $75^{\circ} \mathrm{C}$ in a vacuum drying oven until constant weight, and thereafter named as Cu-S·PPP-SH.

\subsection{Batch biosorption studies}

The adsorption of $\mathrm{Cr}(\mathrm{III})$ and $\mathrm{Cr}(\mathrm{VI})$ on Cu-S.PPP-SH was studied by batch technique. All the biosorption 
experiments were carried out at room temperature $\left(25 \pm 1^{\circ} \mathrm{C}\right)$ by agitating $50 \mathrm{mg}$ of dried adsorbent with $25 \mathrm{~mL}$ of chromium solution of desired concentration and these samples were thoroughly mixed in $150 \mathrm{ml}$ erlenmeyer flasks on a shaking incubator at $120 \mathrm{rpm}$. To check the influence of solution $\mathrm{pH}$, experiments were investigated at various initial $\mathrm{pH}$ in the range of 0.5-8.0. In the kinetic experiments, batch adsorptions were conducted for different contact times from 0 to $160 \mathrm{~min}$ for $\mathrm{Cr}(\mathrm{III})$, while for $\mathrm{Cr}(\mathrm{VI})$ from 0 to $240 \mathrm{~min}$. In order to obtain the adsorption isotherms, the range of initial concentrations of $\mathrm{Cr}$ (III) and $\mathrm{Cr}(\mathrm{VI})$ varied from 25-1000 $\mathrm{mg} \mathrm{L}^{-1}$. All the experiments were carried out at least thrice. The experimental data of the adsorption process were analyzed to study the adsorption mechanism. At the end of the experiment, the samples were centrifuged at 4000 rpm for $10 \mathrm{~min}$, and residual chromium and copper ions in the supernatant liquid were then determined.

\subsection{Analysis of metal ions}

After adsorption, the total concentration of chromium and copper ions in the remaining supernatant solution were determined by using a flame atomic absorption spectrometer (FAAS) (Perkin-Elmer model AAnalysis200, U.S.A) and a graphite furnace atomic absorption spectrometer (GFAAS) (Shanghai Spectrum model SP-3580AA, China), respectively. The $\mathrm{Cr}(\mathrm{VI})$ concentrations were analyzed by the standard colorimetric 1,5-diphenylcarbazide method, in a UV-visible spectrophotometer (Pgeneral model T6-1650F, China). The $\mathrm{Cr}$ (III) concentrations were determined as the difference between total chromium and $\mathrm{Cr}(\mathrm{VI})$ concentration.

\subsection{Calculations}

In order to obtain the adsorption capacity of the metal ions under different experimental conditions, content of $\mathrm{Cu}(\mathrm{II}), \mathrm{Cr}(\mathrm{III})$ and $\mathrm{Cr}(\mathrm{VI})$ in the residual liquid after absorption with Cu-S.PPP-SH were measured. Amount of $\mathrm{Cr}(\mathrm{III})$ and $\mathrm{Cr}(\mathrm{VI})$ adsorbed $\left(q_{\mathrm{e}}, \mathrm{mg} \mathrm{g}^{-1}\right)$ were calculated according to the following equations:

$$
q_{\mathrm{e}}\left(\mathrm{mg} \mathrm{g}^{-1}\right)=\frac{\left(C_{0}-C_{\mathrm{i}}\right) \times V}{M}
$$

where $C_{0}\left(\mathrm{mg} \mathrm{L}^{-1}\right)$ and $C_{\mathrm{i}}\left(\mathrm{mg} \mathrm{L}^{-1}\right)$ are the initial and equilibrium chromium ions concentrations during the adsorption, respectively. $V(\mathrm{~mL})$ is the volume of the solution and $M(\mathrm{mg})$ is the weight of the dry adsorbent.

\subsection{Characterization of the adsorbents}

Fourier transform infrared spectroscopy (FTIR) and scanning electron microscopy (SEM) studies were carried on Cu-S.PPP-SH to determine its modification mechanism and adsorption mechanism. The surface functional groups of the adsorbents were characterized by FTIR. FTIR spectra of the native and modified adsorbents were taken with a FTIR (Thermo Fisher Scientific model Nicolet iS10, U.S.A). The surface morphology of the biosorbents was investigated by SEM (Zeiss model LIGMA HD/VP, Germany).

\subsection{The practical application of the adsor- bents and desorption studies}

In order to study the possibility of repeated use of $\mathrm{Cu}$ S.PPP-SH, the efficiency of chromium removal was also tested using hexavalent chromium-electroplating wastewater and trivalent chromium-tanning wastewater. $0.5 \mathrm{~g}$ Cu-S.PPP-SH was added to a conical flask containing $100 \mathrm{~mL}$ of electroplating wastewater or tanning wastewater sample and shaken at $25^{\circ} \mathrm{C}$ for $90 \mathrm{~min}$. Adjust the $\mathrm{pH}$ of the solution to the desired value by adding acid or base. After centrifugation, the filtered residue was then transferred to another conical flask and stirred with $50 \mathrm{~mL}$ of $0.1 \mathrm{~mol} \mathrm{~L}^{-1}$ $\mathrm{NH}_{3} \cdot \mathrm{H}_{2} \mathrm{O}$ solution (electroplating wastewater-adsorbent) or $\mathrm{HCl}$ solution (tanning wastewater-adsorbent) for 60 min. After stirring, the regenerated adsorbent was washed several times with DDW and dried at $75^{\circ} \mathrm{C}$ for $24 \mathrm{~h}$ in an oven. The adsorption and desorption procedures were repeated three times by using the same adsorbent.

Ethical approval: The conducted research is not related to either human or animals use.

\section{Results and discussion}

\subsection{Preparation and characterization of Cu-S.PPP-SH}

Scheme S1 (Supplementary Information, Scheme S1) illustrates the possible chemical reaction in the chemical modification process for Cu-S.PPP-SH. According to the structural feature of PPP, the soaking treatment with sodium hydroxide can not only increase the amount of hydroxyl groups in the adsorbent, it also causes the adsorbent to swell, which increases the porosity and the specific surface area (Scheme S1a). The purpose of the 
addition of mercaptoacetic acid is to introduce a large amount of sulfydryl groups (Scheme S1b). The chemical reaction of copper sulfate and sulfhydryl highly leads to the formation of copper-sulfur bond, which yields a closed-loop system on the surface of the adsorbent (Scheme S1c). The addition of sodium sulfide opens the closed-loop system (to a open-loop system), and results in the formation of $\mathrm{Cu}-\mathrm{S}$ nanospheres on the surface of the adsorbent (Scheme S1d).

The FTIR spectra of PPP, PPP-OH, PPP-SH and $\mathrm{Cu}-\mathrm{S} \cdot \mathrm{PPP}-\mathrm{SH}$ are shown in Figure 1. In all spectra, the broad and intense absorption peaks around $3326 \mathrm{~cm}^{-1} \mathrm{can}$ be attributed to the $-\mathrm{OH}$ stretching vibration, confirms the existence of "free" and intermolecular bonded hydroxyl groups on the adsorbent surface. The strong $\mathrm{C}-\mathrm{O}$ band at $1037 \mathrm{~cm}^{-1}$ due to $\mathrm{C}-\mathrm{O}-\mathrm{C}$ group confirms the presence of lignin structure of adsorbents. Referring to spectra of PPP and PPP-OH, it can be seen that the intense peak at 1735 $\mathrm{cm}^{-1}$, the one attributed to the $\mathrm{C}=\mathrm{O}$ stretching vibration of methyl esterified carboxylic $\left(-\mathrm{COOCH}_{3}\right)$ group, was drastically weakened from spectrum of PPP to spectrum of PPP-OH, indicating that, in the presence of a base, the adsorbent was subjected to esterolysis as the fiber was swelled during modification [21-23]. Additionally, a new peak at $1714 \mathrm{~cm}^{-1}$ present in spectrum of PPP-SH might be attributed to the formation of mercaptoacetate by grafting the mercaptoacetic acid to the main chain of the adsorbent. Furthermore, in spectrum of Cu-S.PPP-SH, the peak of mercaptoacetate was disappeared, indicating the formation of $\mathrm{Cu}-\mathrm{S}$ molecules. The peak of the ether bond was red-shifted from $1035 \mathrm{~cm}^{-1}$ to $1022 \mathrm{~cm}^{-1}$, also demonstrated the changes of the cellulose structures and the formation of molecular $\mathrm{Cu}-\mathrm{S}$ within the muscular layer. The well-dispersed active $\mathrm{Cu}-\mathrm{S}$ could be contributed to the high efficiency of the modified adsorbent to absorb the $\mathrm{Cr}(\mathrm{III})$ and $\mathrm{Cr}(\mathrm{VI})$.

The SEM micrographs of unmodified and chemically modified adsorbents were shown in Figure S1 (SI, Figure S1). Based on our observations, the untreated PPP had a smooth surface (Figure S1a), showing the typical characteristics of cellulose, hemicellulose and lignose. After treatment in alkaline swelling, the adsorbent surface became rough, loose and porous (Figure S1b). Introducing of carbon-sulphur double bonds through surface modification with mercaptoacetic acid strengthened the molecular interactions on the adsorbent surface, and surface morphology of adsorbent became more diffused and non-compact (Figure S1c). Adding of cupric sulfate and sodium sulfide to the modified system yielded large amounts of uniform, lustrous and highly-ordered $\mathrm{Cu}-\mathrm{S}$ nanospheres deposited on the adsorbent surface. These

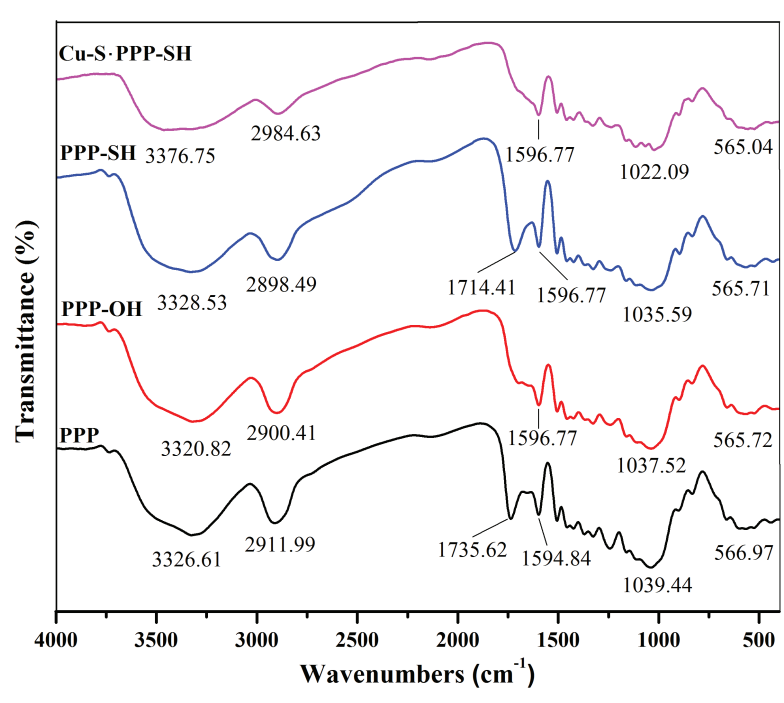

Figure 1: FTIR spectra of PPP, PPP-OH, PPP-SH and Cu-S.PPP-SH.

are spherical in shape, and sized 10-20nm (Figures S1d-f). The introduction of these $\mathrm{Cu}-\mathrm{S}$ nanospheres greatly enhanced adsorption activity of chromium.

\subsection{Effect of $\mathrm{pH}$}

The $\mathrm{pH}$ of the aqueous solution plays an important role in the heavy metal adsorption processes as it affects ionic forms of metal ions in the solution and surface properties of the adsorbent [24]. The effects of $\mathrm{pH}$ on the adsorption of $\mathrm{Cr}(\mathrm{III})$ and $\mathrm{Cr}(\mathrm{VI})$ by Cu-S.PPP-SH were investigated at different $\mathrm{pH}$ values ranging from 0.5 to 8.0 and the results were shown in Figure 2(a). It can be seen that the adsorption of $\mathrm{Cr}(\mathrm{III})$ steadily with increase in $\mathrm{pH}$ from 0.8 to 6.1 and the maximum adsorption occurs at pH 6.1 (31.14 $\mathrm{mg}^{-1}$ ) but adsorption decreases when $\mathrm{pH}$ is increased further ( $\mathrm{pH}$ 6.1-7.9). On the other hand, adsorption of $\mathrm{Cr}(\mathrm{VI})$ increased with decreasing $\mathrm{pH}$ values ( $\mathrm{pH}$ 7.8-1.9) and maximum adsorption of $\mathrm{Cr}(\mathrm{VI})$ on $\mathrm{Cu}-\mathrm{S} \cdot \mathrm{PPP}-\mathrm{SH}$ was observed at pH 1.9 (44.49 $\left.\mathrm{mg} \mathrm{g}^{-1}\right)$.

The experimental results also showed that under acidic and neutral conditions, no detectable $\mathrm{Cr}(\mathrm{VI})$ was liberated in the $\mathrm{Cr}$ (III)-absorbed system (Figure 2b). It is worth mentioning that, on conducting similar experiments on $\mathrm{Cr}(\mathrm{VI})$ under the same conditions, reduction of $\mathrm{Cr}(\mathrm{VI})$ to $\mathrm{Cr}$ (III) occurred in the $\mathrm{Cr}$ (VI)-absorbed system and the concentration of $\mathrm{Cr}(\mathrm{VI})$ increased with increasing $\mathrm{pH}$ (Figure 2(c)).

In addition, the concentrations of $\mathrm{Cu}(\mathrm{II})$ in the residual liquids of $\mathrm{Cr}$ (III)-absorbed system and $\mathrm{Cr}(\mathrm{VI})$-absorbed 

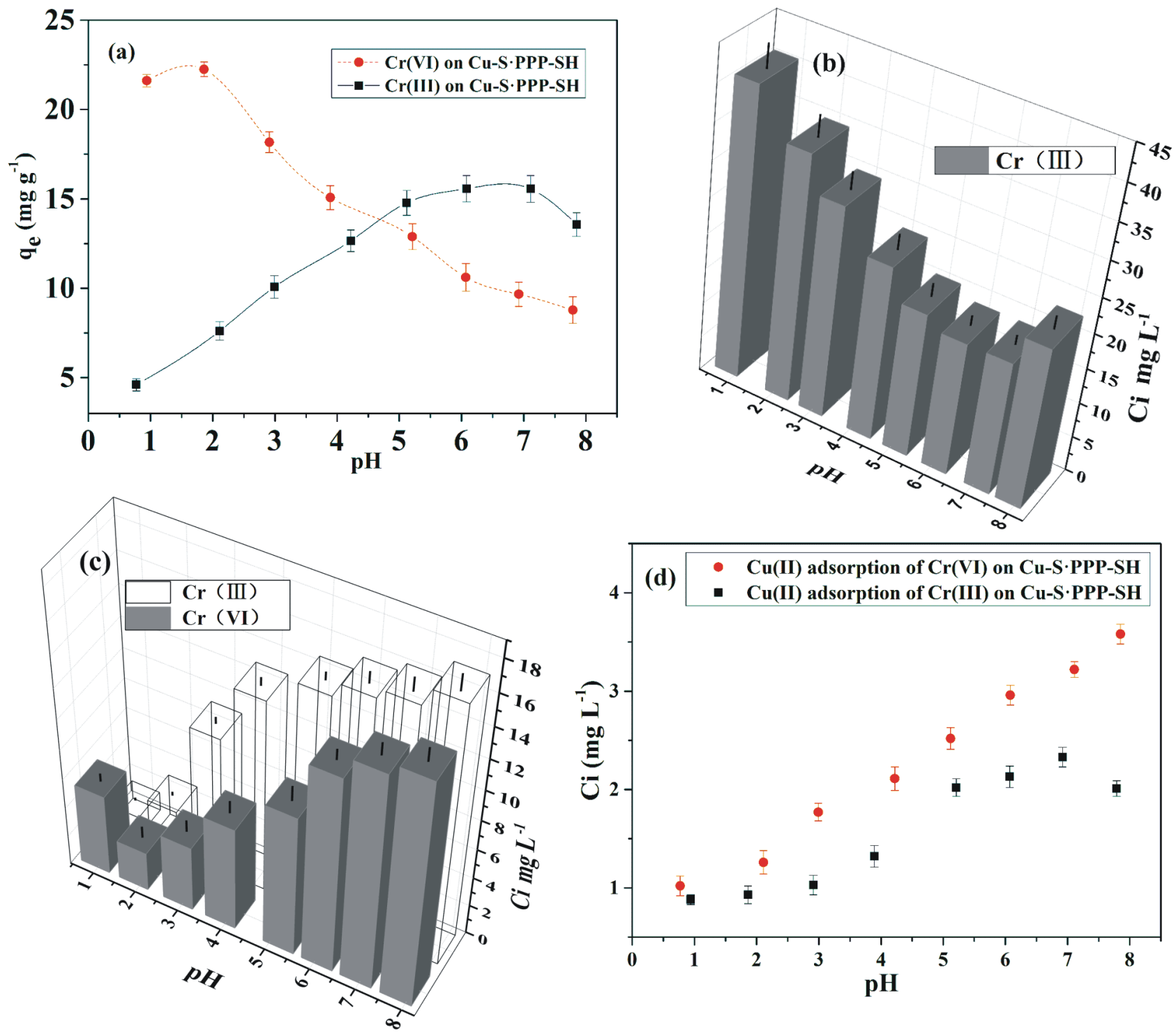

Figure 2: (a) Effect of equilibrium pH on adsorption of $\mathrm{Cr}(\mathrm{III})$ and $\mathrm{Cr}(\mathrm{VI})$ by Cu-S.PPP-SH; (b) Variation of concentrations of chromium ions with $\mathrm{pH}$ after adsorption in the $\mathrm{Cr}(\mathrm{III})$-absorbed system; (c) Variation of concentrations of chromium ions with $\mathrm{pH}$ after adsorption in the $\mathrm{Cr}(\mathrm{VI})$ absorbed system; (d) Variation of concentrations of $\mathrm{Cu}$ (II) with $\mathrm{pH}$ after adsorption in both systems.

Conditions: initial metal ion concentrations $50 \mathrm{mg} \mathrm{L}^{-1}$, adsorbent concentrations $2.0 \mathrm{~g} \mathrm{~L}^{-1}$, temperature $25^{\circ} \mathrm{C}$, contact time $2 \mathrm{~h}$.

system after adsorption were determined, as shown in Figure 2d. It should be noted that the concentrations of $\mathrm{Cu}(\mathrm{II})$ in both systems were also affected by $\mathrm{pH}$. The concentrations of $\mathrm{Cu}(\mathrm{II})$ increased significantly as the $\mathrm{pH}$ increased in $\mathrm{Cr}(\mathrm{VI})$-absorbed system. However in $\mathrm{Cr}(\mathrm{III})$ absorbed system, the concentrations of $\mathrm{Cu}(\mathrm{II})$ increased at first and the decreased, and the trend were similar to that of the effect of $\mathrm{pH}$ on the adsorption of $\mathrm{Cr}(\mathrm{III})$. Meanwhile, it also can be seen that the concentration of $\mathrm{Cu}(\mathrm{II})$ in $\mathrm{Cr}$ (III)-absorbed system was clearly higher than that in $\mathrm{Cr}(\mathrm{VI})$-absorbed system. Obviously, the both adsorption mechanisms were different for the treatment of $\mathrm{Cr}$ (III) or
$\mathrm{Cr}(\mathrm{VI})$ by $\mathrm{Cu}-\mathrm{S} \cdot \mathrm{PPP}-\mathrm{SH}$ as an adsorbent material. We will be discussing mechanism of adsorption in detail in a separate chapter.

\subsection{Adsorption kinetics}

The kinetics of the adsorption describes the rate of the adsorption process and determines the rate-controlling step, and meanwhile provides valuable insight into the reaction pathways and the mechanism of the adsorption reaction $[25,26]$. Figure S2 (SI, Figure S2) shows the effect 
of contact time on batch adsorption of $\mathrm{Cr}(\mathrm{III})$ and $\mathrm{Cr}(\mathrm{VI})$ on Cu-S.PPP-SH. It is obvious that the adsorption of $\mathrm{Cr}(\mathrm{VI})$ quickly increased within first $60 \mathrm{~min}$ and then become almost stable within 120-240 min. The adsorption process of $\mathrm{Cr}(\mathrm{III})$ is similar as compared with that of $\mathrm{Cr}(\mathrm{VI})$. The adsorption capacity of $\mathrm{Cr}(\mathrm{III})$ sharply increases with increasing contact time in the initial stage, and the equilibrium state was attained in about $120 \mathrm{~min}$. A further increase in contact time has a negligible effect on the adsorption capacity of $\mathrm{Cr}$ (III). Furthermore, it significantly showed that the equilibrium adsorption capacity of $\mathrm{Cr}(\mathrm{VI})$ was higher than $\mathrm{Cr}(\mathrm{III})$.

In order to further clarify the adsorption mechanism of $\mathrm{Cr}$ (III) and $\mathrm{Cr}$ (VI) onto Cu-S.PPP-SH, the pseudo-firstorder, pseudo-second-order and intra-particle diffusion kinetic models were applied to evaluate the experimental data. The equations and theoretical aspects of these three kinetic models were introduced in Text S1 (SI, Text S1).

Figure 3(a) shows the plots of the pseudo-first-order rate equation and the corresponding parameters of the pseudo-first-order kinetic equation are given in Table S1 (SI, Table S1). Although the values of correlation coefficient $\left(R^{2}\right)$ were higher than 0.95 , the experimental $q_{\mathrm{e}}$ values $\left(q_{\mathrm{e}} / \exp \right)$ do not agree with the theoretical $q_{\mathrm{e}}$ values $\left(q_{\mathrm{e}} / \mathrm{cal}\right)$ calculated from pseudo-first-order kinetic model. Therefore, it can be concluded that the experimental data for $\mathrm{Cr}(\mathrm{III})$ and $\mathrm{Cr}(\mathrm{VI})$ adsorption onto Cu-S-PPP-SH did not follow the pseudo-first-order kinetics.

The plots of the pseudo-second-order equation are shown in Figure 3b, which shows a excellent straight line relation, and $R^{2}$ values were very close to 1 (Table S1). Furthermore, it was observed that the experimental $q_{\mathrm{e}}$ values $\left(q_{\mathrm{e}} / \exp \right)$ agree very well with the theoretical $q_{\mathrm{e}}$ values $\left(q_{\mathrm{e}} / \mathrm{cal}\right)$ calculated from pseudo-secondorder kinetic model. This indicated that the adsorption processes of $\mathrm{Cr}(\mathrm{III})$ and $\mathrm{Cr}(\mathrm{VI})$ on $\mathrm{Cu}-\mathrm{S}$-PPP-SH could be well described by the pseudo-second-order kinetic model. It also suggested the adsorption rate was controlled by chemical adsorption.

The intra-particle diffusion plots showed multilinearity correlation, as illustrated in Figure 3c. The results showed that the intra-particle diffusion of the adsorption of $\mathrm{Cr}(\mathrm{III})$ on Cu-S.PPP-SH occurred in two different stages (Table S1). At the initial steep-sloped portion, it was deemed as an external surface adsorption or rapid external diffusion. The second linear portion indicates gradual adsorption stage where intra-particle diffusion was the rate-limiting step [27]. In comparison, it was shown that the intra-particle diffusion of the adsorption of $\mathrm{Cr}(\mathrm{VI})$ was a three-step (Table S1). The first sharper portion may be interpreted as an instantaneous adsorption stage or external surface adsorption. The second portion describes the gradual adsorption stage where intra-particle diffusion was rate-controlled. The third portion was the final equilibrium stage where intraparticle diffusion starts to slow down due to the solute concentration becoming lower [28,29].

In addition, Figure $3 \mathrm{~d}$ shows the changes in the concentration of $\mathrm{Cu}$ (II) over time in $\mathrm{Cr}$ (III)-absorbed system and $\mathrm{Cr}(\mathrm{VI})$-absorbed system, respectively. Obviously, in the first 30 minutes, the concentration of $\mathrm{Cu}$ (II) increases abruptly in both systems. The concentration of $\mathrm{Cu}$ (II) quickly reaches plateau after $30 \mathrm{~min}$, with a slight increase as a function of time.

\subsection{Adsorption isotherm}

The influence of initial chromium concentration on the adsorption of $\mathrm{Cr}(\mathrm{III})$ and $\mathrm{Cr}(\mathrm{VI})$ by $\mathrm{Cu}-\mathrm{S} \cdot \mathrm{PPP}-\mathrm{SH}$ was investigated and shown in Figure 4a. The plots revealed that the amount of both metals adsorbed increased with the increase in initial metal ion concentration until a saturation state was reached. The results of these experiments indicate that there were no more adsorption sites on the adsorption surface of Cu-S.PPP-SH, due to the increase in metal ion concentration gradient. Besides, it is also observed that $\mathrm{Cr}(\mathrm{VI})$ is more easily to be absorbed by Cu-S-PPP-SH as compared with $\mathrm{Cr}$ (III) under the same metal ion concentration. With the increase of metal ion concentration, such absorption effect will be increasingly significant.

The adsorption isotherms reveal the specific relation between the concentration of the adsorbate and its adsorption degree onto adsorbent surface at a constant temperature [21]. Therefore, in this study, the most widely used Langmuir and Freundlich models were employed to describe the uptake of $\mathrm{Cr}(\mathrm{III})$ and $\mathrm{Cr}(\mathrm{VI})$ by Cu-S.PPP-SH. The meanings and equations of both models were introduced in Text S2 (SI, Text S2).

The adsorption experimental data were fitted by linear regression to both the Langmuir and Freundlich isotherm models (Figure $4 \mathrm{~b}, \mathrm{c})$. The isotherm parameters $\left(q_{\mathrm{m}}, b\right.$, $K_{\mathrm{F}}$ and $n$ ) and correlation coefficients $\left(R^{2}\right)$ are listed in Table1. The estimation of the correlation coefficients shows that the Langmuir isotherm $\left(R^{2}=0.9980\right)$ exhibited a better fit to the experimental data of $\mathrm{Cr}$ (III) on Cu-S.PPP-SH than the Freundlich isotherm $\left(R^{2}=0.9073\right)$. This result seem to indicate that $\mathrm{Cr}$ (III) adsorption by Cu-S.PPP-SH was more likely monolayer surfaced adsorption. While for $\mathrm{Cr}(\mathrm{VI})$, the higher R2 (>0.98) values showed that the above both models fit well with the experimental data for 

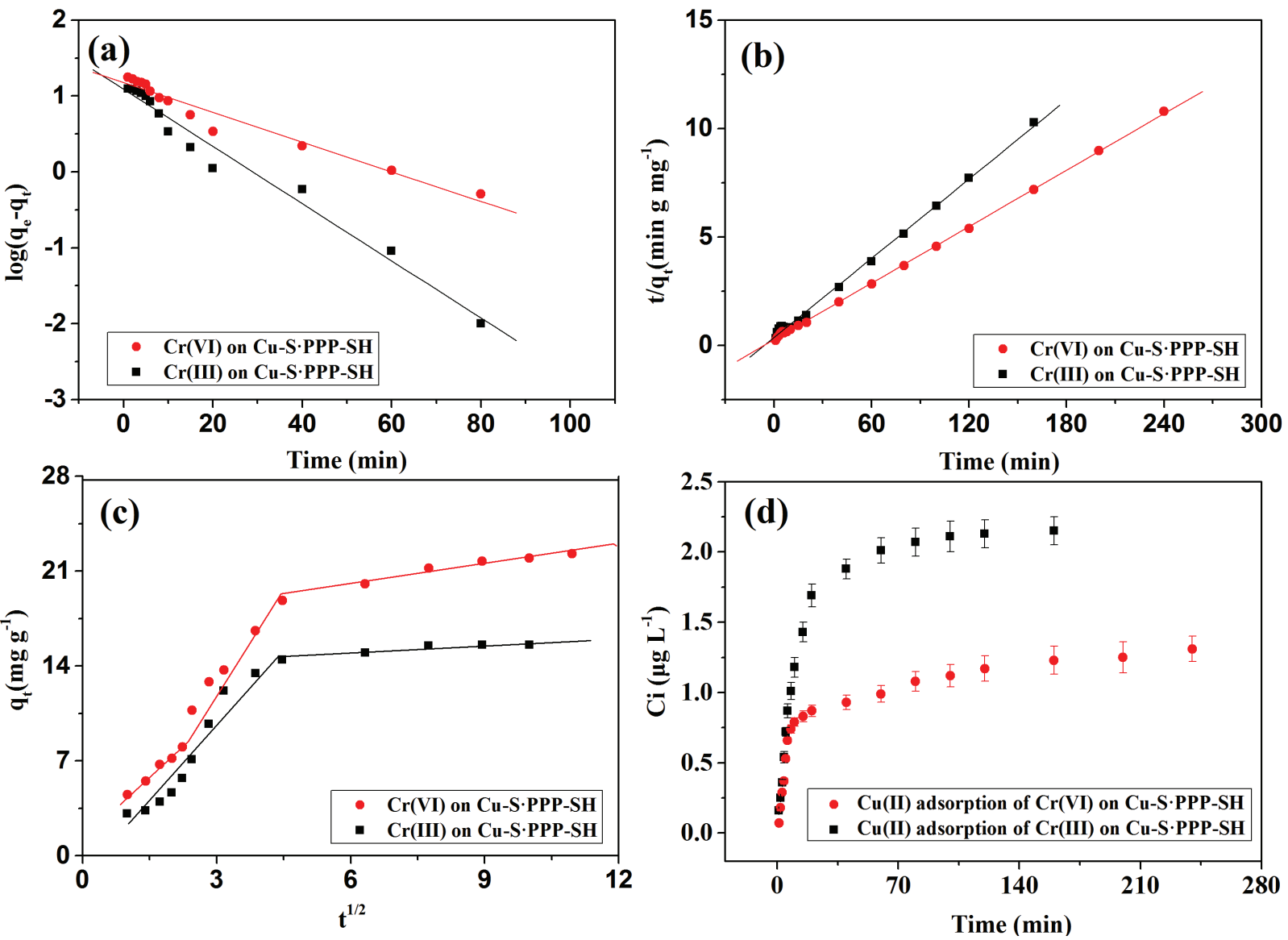

Figure 3: (a) Pseudo-first-order kinetics plot; (b) Pseudo-second-order kinetics plot;(c) Intra-particle diffusion kinetic plot; (d) Variation of concentrations of $\mathrm{Cu}(\mathrm{II})$ with time after adsorption in both systems.

$\mathrm{Cu}-\mathrm{S} \cdot \mathrm{PPP}-\mathrm{SH}$, though Langmuir isotherm fit was giving a better correlation coefficient. This indicates that the $\mathrm{Cr}(\mathrm{VI})$ adsorption was heterogeneous adsorption, which was complex process involving more than one mechanism of surface binding.

According to the Langmuir model, the maximum adsorption capacity $\left(q_{\mathrm{m}}\right)$ of $\mathrm{Cr}(\mathrm{III})$ and $\mathrm{Cr}(\mathrm{VI})$ on $\mathrm{Cu}$-S.PPP-SH were $52.30 \mathrm{mg} \mathrm{g}^{-1}$ and $94.25 \mathrm{mg} \mathrm{g}^{-1}$, respectively. Compared to $\mathrm{Cr}(\mathrm{III}), \mathrm{Cu}-\mathrm{S} \cdot \mathrm{PPP}-\mathrm{SH}$ exhibits good adsorption properties for $\mathrm{Cr}(\mathrm{VI})$. The maximum adsorption capacity of $\mathrm{Cr}(\mathrm{III})$ and $\mathrm{Cr}(\mathrm{VI})$ obtained in this work are compared with those of some other adsorbents reported in literature are given in Table 2.

Remarkably, Figure 4(d) presented the concentration curve of $\mathrm{Cu}(\mathrm{II})$ in solution after absorbing different concentrations of $\mathrm{Cr}(\mathrm{III})$ and $\mathrm{Cr}(\mathrm{VI})$ with $\mathrm{Cu}$-S.PPP-SH. It showed that the with the increase of $\mathrm{Cr}$ (III) concentration, $\mathrm{Cu}$ (II) concentration first slightly increases and then tends to be stable. For $\mathrm{Cr}(\mathrm{VI}), \mathrm{Cu}(\mathrm{II})$ concentration always increases with $\mathrm{Cr}(\mathrm{VI})$ concentration after the absorption
Table 1: Langmuir and Freundlich parameters of $\mathrm{Cr}(\mathrm{III})$ and $\mathrm{Cr}(\mathrm{VI})$ adsorption on Cu-S.PPP-SH.

\begin{tabular}{lllllll}
\hline Metals & \multicolumn{2}{l}{ Langmuir } & \multicolumn{5}{c}{ Freundlich } \\
& $\boldsymbol{q}_{\mathrm{m}}\left(\mathrm{mg} \mathrm{g}^{-1}\right)$ & $\boldsymbol{b}\left(\mathrm{L} \mathrm{mg}^{-1}\right)$ & $\boldsymbol{R}^{2}$ & $\boldsymbol{K}_{f}$ & $\boldsymbol{n}$ & $\boldsymbol{R}^{2}$ \\
\hline $\mathrm{Cr}(\mathrm{III})$ & 52.30 & 0.0123 & 0.9980 & 4.0168 & 2.5863 & 0.9073 \\
$\mathrm{Cr}(\mathrm{VI})$ & 94.25 & 0.0089 & 0.9859 & 6.3211 & 2.5568 & 0.9965 \\
\hline
\end{tabular}

using Cu-S.PPP-SH. These also suggested that Cu-S·PPP-SH absorbed $\mathrm{Cr}(\mathrm{III})$ and $\mathrm{Cr}(\mathrm{VI})$ with different mechanisms.

\subsection{Mechanism of adsorption}

Figure 5 and Scheme 2 (SI, Scheme S2) shows the possible reaction mechanism for Cu-S.PPP-SH, which adsorb $\mathrm{Cr}$ (III) and $\mathrm{Cr}(\mathrm{VI})$ through oxide-reduction, or ion exchange, or by a combination of multiple processes. Combined with the analysis of Figure 1, Figure 2 and Figure S1, we can draw the following conclusions. 

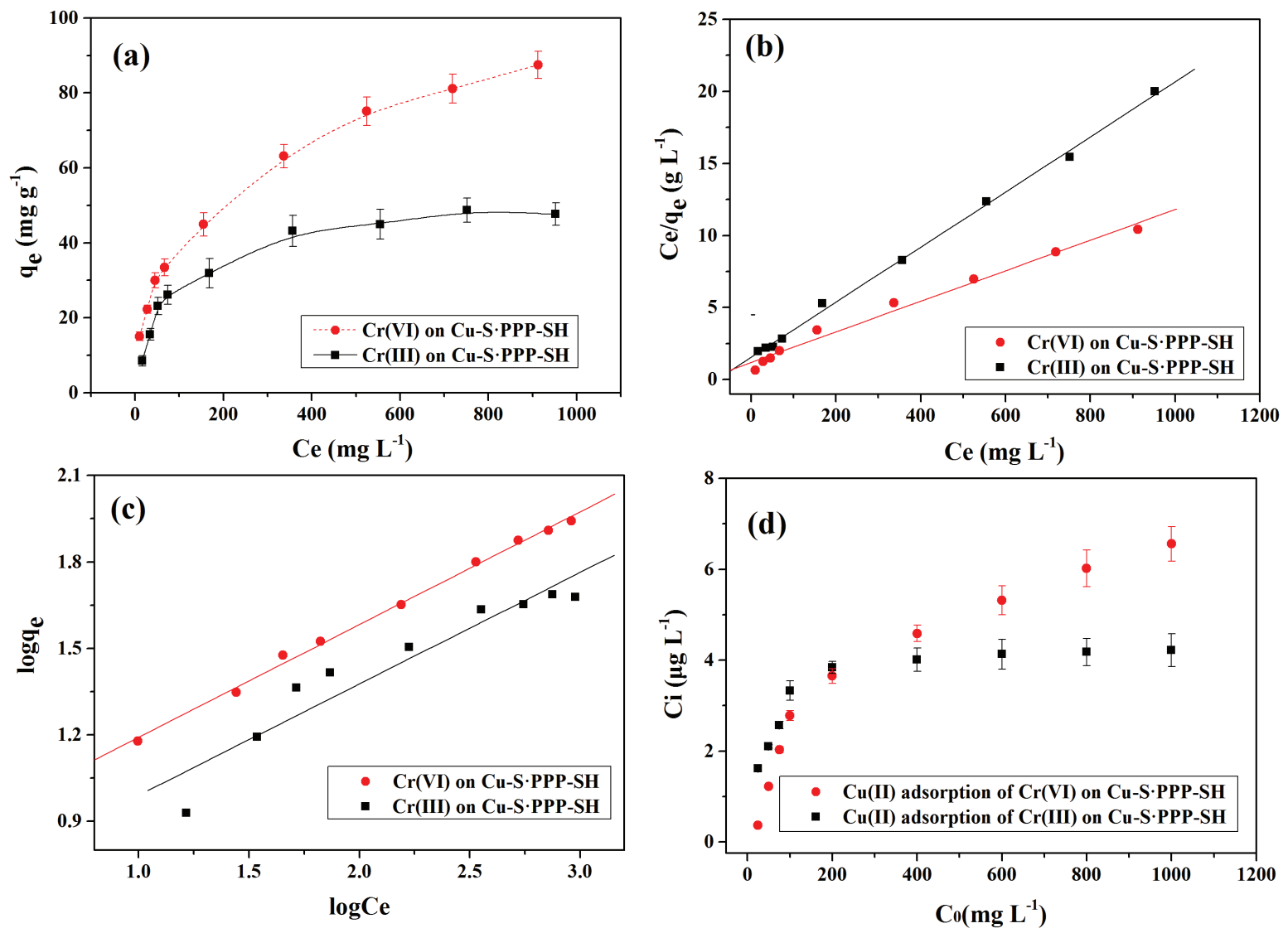

Figure 4: (a) Effect of initial chromium ion concentration on adsorption of $\mathrm{Cr}(\mathrm{III})$ and $\mathrm{Cr}(\mathrm{VI})$ by Cu-S.PPP-SH; (b) Langmuir adsorption isotherm for $\mathrm{Cr}(\mathrm{III})$ and $\mathrm{Cr}(\mathrm{VI})$; (c) Frendulich adsorption isotherm for $\mathrm{Cr}(\mathrm{III})$ and $\mathrm{Cr}(\mathrm{VI})$; (d) Variation of concentrations of $\mathrm{Cu}(\mathrm{II})$ with initial chromium ion concentration after adsorption in both systems. Conditions: $\mathrm{pH} 6.1$ and 1.9 for $\mathrm{Cr}(\mathrm{III})$ and $\mathrm{Cr}(\mathrm{VI})$, adsorbent concentrations $2.0 \mathrm{~g} \mathrm{~L}{ }^{-1}$, temperature $25^{\circ} \mathrm{C}$, contact time $2 \mathrm{~h}$.

Table 2: The list of some agriculture by-products for adsorption of $\mathrm{Cr}(\mathrm{III})$ and $\mathrm{Cr}(\mathrm{VI})$ in the literature.

\begin{tabular}{llll}
\hline Adsorbent & \multicolumn{2}{l}{$\boldsymbol{q}_{\mathrm{m}}\left(\mathrm{mg} \mathrm{g}^{-1}\right)$} & References \\
& $\mathrm{Cr}(\mathrm{III})$ & $\mathrm{Cr}(\mathrm{VI})$ & \\
\hline Agave Lechuguilla & 63.69 & 33.55 & {$[18]$} \\
Cassia fistula & 85.71 & 90.81 & {$[19]$} \\
Leersia hexandra Swartz & 28.64 & 2.51 & {$[30]$} \\
Citrus reticulata & 232.55 & 263.15 & {$[31]$} \\
Atriplex canescens & 3.01 & 0.59 & {$[32]$} \\
Lignin & 25.00 & 9.30 & {$[33]$} \\
Borassus aethiopum & 6.24 & 7.13 & {$[34]$} \\
Nannochloris oculata & 31.70 & 37.70 & {$[35]$} \\
Cu-S.PPP-SH & 52.30 & 94.25 & This study \\
\hline
\end{tabular}

Hexavalent chromium exists in different forms such as salts of chromic acid $\left(\mathrm{H}_{2} \mathrm{CrO}_{4}\right)$, hydrogen chromate ion $\left(\mathrm{HCrO}_{4}^{-}\right)$and chromate ion $\left(\mathrm{CrO}_{4}^{2-}\right.$ and $\left.\mathrm{Cr}_{2} \mathrm{O}_{7}{ }^{2-}\right)$ in aqueous solutions, and the stability of these forms is dependent on the $\mathrm{pH}$ of the system. At lower $\mathrm{pH}$ values (1-1.5), $\mathrm{H}_{2} \mathrm{CrO}_{4}$ is the existent species, and the dominant form of $\mathrm{Cr}(\mathrm{VI})$ is $\mathrm{HCrO}_{4}^{-}$between $\mathrm{pH} 1.5$ and 4.0. Increasing the $\mathrm{pH}$ will shift the concentration of $\mathrm{HCrO}_{4}^{-}$to other forms: $\mathrm{CrO}_{4}{ }^{2-}$ and $\mathrm{Cr}_{2} \mathrm{O}_{7}^{2-}[23,36,37]$.

It can be seen from the SEMresults that there were many $\mathrm{Cu}-\mathrm{S}$ nanospheres on the surface of Cu-S.PPP-SH, which may reduce the $\mathrm{Cr}(\mathrm{VI})$ in the solution into $\mathrm{Cr}$ (III). At the meantime, Cr (III) may react with the mercapto groups in the adsorbent to achieve the adsorption of chromium ions on the adsorbent. At lower $\mathrm{pH}$, the surface of Cu-S.PPP-SH will be surrounded by high quantities of hydronium ions $\left(\mathrm{H}_{3} \mathrm{O}^{+}\right)$, which is beneficial to reduction reaction. As the $\mathrm{pH}$ value increases, and the concentration of $\mathrm{H}_{3} \mathrm{O}^{+}$decreases, reduction reaction weakens. Consequently, the amount of the $\mathrm{Cr}(\mathrm{VI})$ reduced into $\mathrm{Cr}$ (III) decreases, and the capability of the adsorbent for adsorbing $\mathrm{Cr}(\mathrm{VI})$ decreases. In addition, if the concentration of $\mathrm{H}_{3} \mathrm{O}^{+}$is excessively high, the $\mathrm{H}_{3} \mathrm{O}^{+}$will compete with the $\mathrm{Cr}$ (III) formed in the solution for the reactive sites on the adsorbent, which 


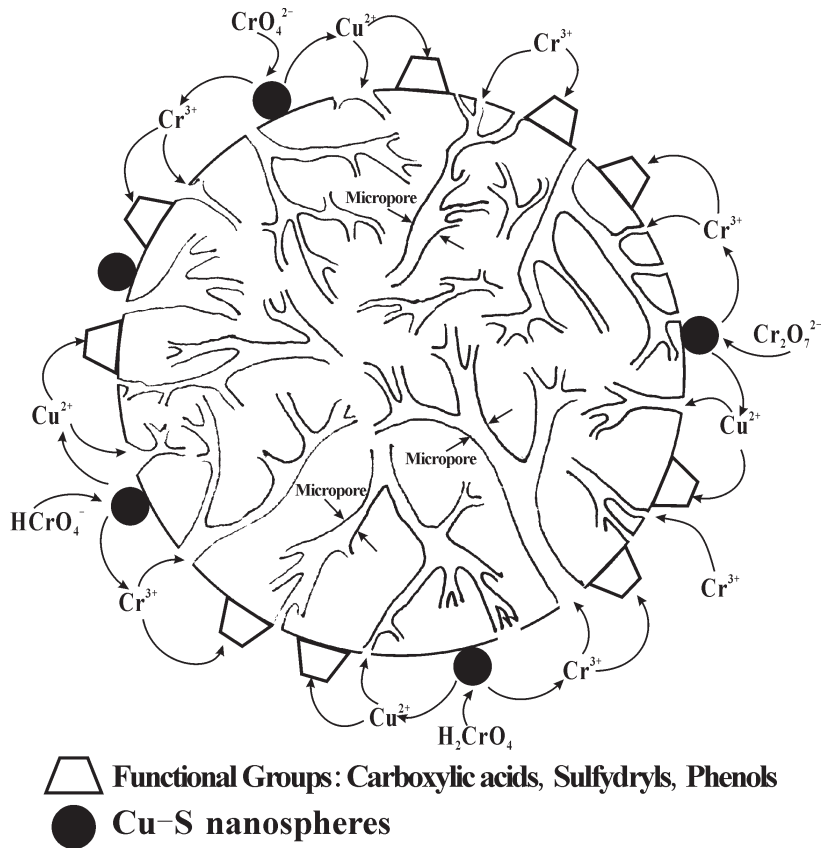

Figure 5: Mechanism of the adsorption for $\mathrm{Cr}(\mathrm{III})$ and $\mathrm{Cr}(\mathrm{VI})$ on $\mathrm{Cu}$ S.PPP-SH.

hinders the reduction of $\mathrm{Cr}(\mathrm{VI})$ into $\mathrm{Cr}(\mathrm{III})$ to some extent. As a result, the optimal $\mathrm{pH}$ value for $\mathrm{Cu}$-S.PPP-SH adsorbing $\mathrm{Cr}(\mathrm{VI})$ is 1.9. Moreover, since the $\mathrm{S}-\mathrm{Cu}$ has a lower electric potential, the reduction reaction is completely carried out. The reaction rate is controlled by the diffusion rates of the reactants as well as the migration rates of the reactants within the channel. The reduced product $\mathrm{Cr}$ (III) can enter the channel of adsorbent with functions of ion exchange. Meanwhile, the positive charge of the $\mathrm{Cr}$ (III) promotes the progression of the reduction reaction of $\mathrm{Cr}(\mathrm{VI})$. Therefore, the most possible chemical adsorption mode of $\mathrm{Cr}(\mathrm{VI})$ was a combination of oxide-reduction and ion exchange, (a) and (b) are the most possible chemical adsorption process.

However, $\mathrm{Cr}(\mathrm{III})$ is cationic in solution under acid

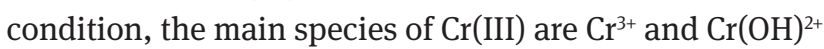
$[35,38]$. At $\mathrm{pH}$ values below $4, \mathrm{H}_{3} \mathrm{O}^{+}$concentration is high, protons would occupy the surface of adsorbent, which can compete strongly with $\mathrm{Cr}$ (III) for the active sites of adsorbent, resulting in lower adsorption capacity. As the $\mathrm{pH}$ level increased $\left(\mathrm{pH}\right.$ 4.0-6.0), $\mathrm{H}_{3} \mathrm{O}^{+}$concentration decreases, resulting in the degree of protonation of the surface of adsorbent decreased gradually, which are conducive to the adsorption of $\mathrm{Cr}$ (III) and thus the adsorption capacity of $\mathrm{Cr}$ (III) increases. When $\mathrm{pH}$ of $\mathrm{Cr}$ (III) was further increased ( $\mathrm{pH}$ 6.0-7.8), the formation of anionic hydroxide complexes $\left(\mathrm{Cr}(\mathrm{OH})_{3}\right)$ decreases the concentration of free $\mathrm{Cr}(\mathrm{III})$ in the solution, thereby the adsorption capacity of $\mathrm{Cr}$ (III) was decreased. In brief, the removal process of $\mathrm{Cr}(\mathrm{III})$ is a kind of adsorption on the surface-porous adsorbent. As the $\mathrm{pH}$ value of the solution increases, there is obvious tendency that soluble Cr(III) should become insoluble hydroxide. In addition, the deionization of functional groups on the surface of adsorbent at the same time also benefits to the adsorption of $\mathrm{Cr}(\mathrm{III})$. This result indicates that the ion exchange may be the principal mechanism for the adsorption of $\mathrm{Cr}$ (III) by Cu-S.PPP-SH, (c) and (d) are the most possible chemical adsorption process.

\subsection{Industrial wastewater adsorption experi- ments and reuse of the adsorbent}

Reusability of adsorbent is an important factor in practical applications for the commercialization of biosorption technology [39]. Cu-S.PPP-SH was applied to the removal of $\mathrm{Cr}(\mathrm{III})$ or $\mathrm{Cr}(\mathrm{VI})$ in electroplating wastewater sample or tanning wastewater sample, respectively. Moreover, in order to demonstrate the reusability of Cu-S.PPP-SH, the adsorption-desorption cycles of $\mathrm{Cr}(\mathrm{III})$ or $\mathrm{Cr}(\mathrm{VI})$ were repeated three times by using the same adsorbent (Table 3). After three cycles, Cu-S.PPP-SH regeneration efficiency decreased slightly after each successive cycle, it is thus clear that the regeneration process was effective. This result also indicates that recovery efficiencies of these two metals remain almost constant with respect to the number of cycles. In addition, it can be seen from Figure S3 (SI, Figure S3) that the morphology of Cu-S.PPP-SH still remains stable after repeated use for three times. Therefore, Cu-S.PPP-SH can be used successfully at least three times after regeneration for the removal $\mathrm{Cr}(\mathrm{III})$ and $\mathrm{Cr}(\mathrm{VI})$ from electroplating wastewater and tanning wastewater.

\section{Conclusion}

Cu-S.PPP-SH has proven to be a potentially useful biosorbent for the removal of $\mathrm{Cr}(\mathrm{III})$ and $\mathrm{Cr}(\mathrm{VI})$ from aqueous solutions. The results of FTIR and SEM studies indicated that the abundant sulfur-containing functional groups on the surface of Cu-S.PPP-SH was beneficial to the adsorption of $\mathrm{Cr}(\mathrm{III})$ and $\mathrm{Cr}(\mathrm{VI})$. The adsorption of $\mathrm{Cr}(\mathrm{III})$ and $\mathrm{Cr}(\mathrm{VI})$ was highly pH-dependent, and the maximum adsorption was found to occur at $\mathrm{pH} 6.1$ and $\mathrm{pH}$ 1.9, respectively. Kinetic studies showed that the adsorption of $\mathrm{Cr}(\mathrm{III})$ and $\mathrm{Cr}(\mathrm{VI})$ followed the pseudosecond-order model, and the intra-particle diffusion was involved in the adsorption process but it was not 
Table 3: Influence of starting effluents and eluents employed during repeated adsorption/desoprtion (A/D) cycles on the regeneration efficiency and chromium recovery efficiency.

\begin{tabular}{|c|c|c|c|c|c|}
\hline Effluents & Metals & Eluents & A/D cycle & $\begin{array}{l}\text { Cu-S.PPP-SH } \\
\text { regeneration efficiency (\%) }{ }^{a}\end{array}$ & $\begin{array}{l}\text { Chromium } \\
\text { recovery efficiency (\%) }\end{array}$ \\
\hline \multirow[t]{3}{*}{ Tanning wastewater ${ }^{A}$} & $\mathrm{Cr}(\mathrm{III})$ & $0.1 \mathrm{~mol} \mathrm{~L}^{-1} \mathrm{HCl}$ & 1 & 91.4 & 74.3 \\
\hline & & & 2 & 90.1 & 72.7 \\
\hline & & & 3 & 88.8 & 69.1 \\
\hline \multirow[t]{3}{*}{ Electroplating wastewater ${ }^{\text {B }}$} & $\mathrm{Cr}(\mathrm{VI})$ & $0.1 \mathrm{~mol} \mathrm{~L}^{-1} \mathrm{NH}_{3} \cdot \mathrm{H}_{2} \mathrm{O}$ & 1 & 94.3 & 84.3 \\
\hline & & & 2 & 92.7 & 81.6 \\
\hline & & & 3 & 91.5 & 77.5 \\
\hline
\end{tabular}

${ }^{a}$ CU-S.PPP-SH regeneration efficiency $(\%)=$ regenerated adsorption capacity / original adsorption capacity $\times 100 \%$.

${ }^{\mathrm{b}}$ Chromium recovery efficiency $(\%)=$ amount of chromium recovered / amount of chromium adsorbed $\times 100 \%$.

A Conditions: $\mathrm{pH} 6.1$, initial $\mathrm{Cr}$ (III) concentrations $74.3 \mathrm{mg} \mathrm{L}^{-1}$, adsorbent concentrations $0.5 \mathrm{~g} \mathrm{~L}^{-1}$, contact time $2 \mathrm{~h}$, temperature $25^{\circ} \mathrm{C}$.

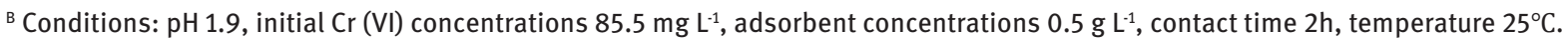

the sole rate-controlling factor. The Langmuir and Freundlich isotherm models were used for the adsorption of chromium ions on Cu-S.PPP-SH, and it was found that the experimental data for $\mathrm{Cr}(\mathrm{III})$ could be described appropriately by Langmuir model, whereas adsorption of $\mathrm{Cr}(\mathrm{VI})$ followed the Freundlich model. In addition, the adsorption mechanism also was discussed, inferred that the most possible chemical adsorption mode of $\mathrm{Cr}(\mathrm{VI})$ was a combination of oxide-reduction and ion exchange, however ion exchange was the main way of adsorbing $\mathrm{Cr}(\mathrm{III})$. Finally, The adsorption-desorption tests showed that $\mathrm{Cu}-\mathrm{S}$-PPP-SH can be reused at least 3 cycles for the removal of $\mathrm{Cr}(\mathrm{III})$ and $\mathrm{Cr}(\mathrm{VI})$ in electroplating wastewater and tanning wastewater.

Acknowledgements: This work is financially supported by the Program for High-end Talent Training in Anshan Science and Technology Bureau, China (No. 20153473).

Conflict of interest: Authors state no conflict of interest.

\section{References}

[1] Karabulut S., Karabakan A., Denizli A., Yürüm Y., Batch removal of copper(II) and zinc(II) from aqueous solutions with low-rank Turkish coals, Sep. Purif. Technol., 2000, 18(3), 177-184.

[2] Nriagu J.O., Pacyna J.M., Quantitative assessment of worldwide contamination of air, water and soils by trace metals, Nature., 1988, 333(6169), 134-139.

[3] Jeon C., Nah I.W., Hwang K.Y., Adsorption of heavy metals using magnetically modified alginic acid, Hydrometallurgy., 2007, 86(3), 140-146.
[4] Gupta V.K., Chandra R., Tyagi I., Verma M., Removal of hexavalent chromium ions using $\mathrm{CuO}$ nanoparticles for water purification applications, J. Colloid Interface Sci., 2016, 478, 54-62.

[5] Sud D., Mahajan G., Kaur M.P., Agricultural waste material as potential adsorbent for sequestering heavy metal ions from aqueous solutions - a review, Bioresour Technol., 2008, 99(14), 6017-6027.

[6] Wang X., Wei Y., Wang S., Chen L., Red-to-blue colorimetric detection of chromium via $\mathrm{Cr}$ (III)-citrate chelating based on Tween 20-stabilized gold nanoparticles, Colloids and Surfaces A: Physicochem. Eng. Aspects., 2015, 472, 57-62.

[7] Mozumder M.S.I., Khan M.M.R., Islam M.A., Kinetics and mechanism of $\mathrm{Cr}(\mathrm{VI})$ adsorption onto tea-leaves waste, AsiaPac. J. Chem. Eng., 2008, 3(4), 452-458.

[8] Wang X., Pehkonen S.O., Ray A.K., Removal of aqueous Cr(VI) by a combination of photocatalytic reduction and coprecipitation, Ind. Eng. Chem. Res., 2004, 43(7), 1665-1672.

[9] Rafati L. Mahvi A.H., Asgari A.R., Hosseini S.S., Removal of chromium(VI) from aqueous solutions using Lewatit F036 nano ion exchange resin, Int. J. Environ Sci. Te., 2010, 7(1), 147-156.

[10] Alguacil F.J., Alonso M., Lopez F., Lopez-Delgado A., Uphill permeation of $\mathrm{Cr}(\mathrm{VI})$ using Hostarex $\mathrm{A} 327$ as ionophore by membrane-solvent extraction processing, Chemosphere., 2008, 72(4), 684-689.

[11] Wionczyk B., Cierpiszewski R., Mól A., Prochaska K., Studies on the kinetics and equilibrium of the solvent extraction of chromium(III) from alkaline aqueous solutions of different composition in the system with Aliquat 336, J Hazard Mater., 2011, 198(30), 257-268.

[12] Vasudevan S., Lakshmi J., Studies relating to an electrochemically assisted coagulation for the removal of chromium from water using zinc anode, Water Sci Tech-W Sup., 2011, 11(2), 142-150.

[13] Gupta V.K., Rastogi A., Nayak A., Adsorption studies on the removal of hexavalent chromium from aqueous solution using a low cost fertilizer industry waste material, J. Colloid Interface Sci., 2010, 342, 135-141.

[14] Yang S., Li L., Pei Z., Li C., Lv J., Xie J., Wen B., Zhang S., Adsorption kinetics, isotherms and thermodynamics of $\mathrm{Cr}$ (III) on graphene oxide, Colloids and Surfaces A: Physicochem. Eng. Aspects., 2014, 457, 100-106. 
[15] Barrera H., Ureña-Núñez F., Bilyeu B., Barrera-Díaz C., Removal of chromium and toxic ions present in mine drainage by Ectodermis of Opuntia, J Hazard Mater., 2006, B136(3), 846853.

[16] Fiol N., Escudero C., Villaescusa I., Chromium sorption and Cr(VI) reduction to $\mathrm{Cr}$ (III) by grape stalks and yohimbe bark, Bioresour Technol., 2008, 99(11), 5030-5036.

[17] Elangovan R., Philip L., Chandraraj K., Biosorption of chromium species by aquatic weeds: kinetics and mechanism studies, J Hazard Mater., 2008, 152(1), 100-112.

[18] Romero-González J., Gardea-Torresdey J.L., Peralta-Videa J.R., Rodríguez E., Determination of equilibrium and kinetic parameters of the adsorption of $\mathrm{Cr}(\mathrm{III})$ and $\mathrm{Cr}(\mathrm{VII})$ from aqueous solutions to Agave Lechuguilla biomass, Bioinorg. Chem. Appl., 2005, 3(1-2), 55-68.

[19] Abbas M., Nadeem R., Zafar M.N., Arshad M., Biosorption of chromium(III) and chromium(VI) by untreated and pretreated Cassia fistula biomass from aqueous solutions, Water Air Soil Poll., 2008, 191(1-4), 139-148.

[20] Ai T., Jiang X., Yu H., Xu H., Pan D., Liu Q., et al., Equilibrium, kinetic and mechanism studies on the biosorption of $\mathrm{Cu}^{2+}$ and $\mathrm{Ni}^{2+}$ by sulfur-modified bamboo powder, Korean J. Chem. Eng., 2015, 32(2), 342-349.

[21] Rafatullah M., Sulaiman O., Hashim R., Ahmad A., Adsorption of copper (II), chromium (III), nickel (II) and lead (II) ions from aqueous solutions by meranti sawdust, J Hazard Mater., 2009, 170(2-3), 969-977.

[22] Jain M., Garg V.K., Kadirvelu K., Equilibrium and kinetic studies for sequestration of $\mathrm{Cr}(\mathrm{VI})$ from simulated wastewater using sunflower waste biomass, J Hazard Mater., 2009, 171(1-3), 328334.

[23] Garg U.K., Kaur M.P., Garg V.K., Sud D., Removal of hexavalent chromium from aqueous solution by agricultural waste biomass, J Hazard Mater., 2007, 140(1-2), 60-68.

[24] Yu H., Pang J., Ai T., Liu L., Biosorption of $\mathrm{Cu}^{2+}, \mathrm{Co}^{2+}$ and $\mathrm{Ni}^{2+}$ from aqueous solution by modified corn silk: Equilibrium, kinetics, and thermodynamic studies, J. Taiwan Inst. Chem. Eng., 2016, 62, 21-30.

[25] Dursun A.Y., Kalayci Ç.S., Equilibrium, kinetic and thermodynamic studies on the adsorption of phenol onto chitin, J Hazard Mater., 2005, 123(1), 151-157.

[26] Tang P.L., Lee C.K., Low K.S., Zainal Z., Sorption of $\operatorname{Cr}(\mathrm{VI})$ and $\mathrm{Cu}(\mathrm{II})$ in aqueous solution by ethylenediamine modified rice hull, Environ Technol., 2003, 24(10), 1243-1251.

[27] Rahman R.O.A., Ibrahim H.A., Hanafy M., Monem N.M.A., Assessment of synthetic zeolite $\mathrm{Na} \mathrm{A}-\mathrm{X}$ as sorbing barrier for strontium in a radioactive disposal facility, Chem. Eng. J., 2010, 157(1), 100-112.

[28] Hameed B.H., El-Khaiary M.I., Kinetics and equilibrium studies of malachite green adsorption on rice straw-derived char, J Hazard Mater., 2008, 153(1-2), 701-708.

[29] Lu W., Li J., Sheng Y., Zhang X., You J., Chen L., One-pot synthesis of magnetic iron oxide nanoparticle-multiwalled carbon nanotube composites for enhanced removal of $\mathrm{Cr}(\mathrm{VI})$ from aqueous solution, J. Colloid Interface Sci., 2017, 505, 1134-1146.

[30] Li ]., Lin Q., Zhang X., Yan Y., Kinetic parameters and mechanisms of the batch biosorption of $\mathrm{Cr}(\mathrm{VI})$ and $\mathrm{Cr}(\mathrm{III})$ onto Leersia hexandra Swartz biomass, J. Colloid. Interf. Sci., 2009, 333(1), 71-77.
[31] Zubair A., Bhatti H.N., Hanif M.A., Shafqat F., Kinetic and equilibrium modeling for $\mathrm{Cr}(\mathrm{III})$ and $\mathrm{Cr}(\mathrm{VI})$ removal from aqueous solutions by Citrus reticulata waste biomass, Water Air Soil Poll., 2008, 191(1-4), 305-318.

[32] Sawalha M.F., Peralta-Videa J.R., Romero-González J., GardeaTorresdey J.L., Biosorption of $\mathrm{Cd}(\mathrm{II}), \mathrm{Cr}(\mathrm{III})$, and $\mathrm{Cr}(\mathrm{VI})$ by saltbush (Atriplex canescens) biomass: Thermodynamic and isotherm studies, J. Colloid. Interf. Sci., 2006, 300(1), 100-104.

[33] Demirbaş A., Adsorption of $\mathrm{Cr}(\mathrm{III})$ and $\mathrm{Cr}(\mathrm{VI})$ ions from aqueous solutions on to modified lignin, Energy Sources., 2005, 27(15), 1449-1455.

[34] Elangovan R., Philip L., Chandraraj K., Biosorption of hexavalent and trivalent chromium by palm flower (Borassus aethiopum), Chem. Eng. J., 2008, 141(1), 99-111.

[35] Kim E.J., Park S., Hong H.J., Choi Y.E., Yang J.W., Biosorption of chromium $(\mathrm{Cr}(\mathrm{III}) / \mathrm{Cr}(\mathrm{VII}))$ on the residual microalga Nannochloris oculata after lipid extraction for biodiesel production, Bioresour Technol., 2011, 102(24), 11155-11160.

[36] Levankumar L., Muthukumaran V., Gobinath M.B., Batch adsorption and kinetics of chromium (VI) removal from aqueous solutions by Ocimum americanum L. seed pods, J Hazard Mater., 2009, 161(2-3), 709-713.

[37] Anupam K., Dutta S., Bhattacharjee C., Datta S., Adsorptive removal of chromium (VI) from aqueous solution over powdered activated carbon: Optimisation through response surface methodology, Chem. Eng. J., 2011, 173(1), 135-143.

[38] Kushwaha S., Sreedhar B., Sudhakar P.P., A spectroscopic study for understanding the speciation of $\mathrm{Cr}$ on palm shell based adsorbents and their application for the remediation of chrome plating effluents, Bioresour Technol., 2012, 116(4), 15-23.

[39] Argun M.E., Dursun S., A new approach to modification of natural adsorbent for heavy metal adsorption, Bioresour Technol., 2008, 99(7), 2516-2527. 